\title{
Physiologic Type Reconstruction in Complicated Corrosive Strictures of Upper Gastrointestinal Segment
}

\author{
L. Kotsis ${ }^{1 *}$, Z. Krisár ${ }^{2 \#, ~ P . ~ V a d a ́ s z ~}{ }^{1}$ \\ ${ }^{1}$ Thoracic Surgical Department of National Korányi Tbc and Pulmonology Institute, Budapest, Hungary \\ ${ }^{2}$ Department of Surgery, Hospital Oradea, Romina \\ Email: ${ }^{*}$ kotsisdr@gmail.com
}

Received 4 March 2015; accepted 22 April 2015; published 24 April 2015

Copyright (C) 2015 by authors and Scientific Research Publishing Inc.

This work is licensed under the Creative Commons Attribution International License (CC BY). http://creativecommons.org/licenses/by/4.0/

(c) (i) Open Access

\begin{abstract}
Objectives: The main steps for physiologic type reconstruction in 50 complicated corrosive strictures of upper alimentary tract are presented. Methods: In successive developed gastric outlet and esophageal strictures a limited Billroth I resection (in 9) or conversion a prior precolic GEA in such anastomosis (in 5) and middle or total gastrectomies (in 3) were performed. A second stage substernal by-pass with isoperistaltic transverse colon segment was done 6 - 12 weeks later. In all but one instances the graft was implanted high in the gastric stump. In extensive burned and retracted such lesion (in 3) a similar by-pass was carried out but the lower anastomosis was done with the not involved prepyloric segement. In concomittant antropyloric and esophageal strictures in 11 young, good risk patients, a limited Billroth I resction and simultaneous colonic bypass was used. In case of accompanied respiratory fistula (in 4) exclusion by-pass was useful for both lesions. The associated pyloric stricture (in 3 ) was solved at the same time. Side-to-end pharyngocolostomy was used in 4 high thoracocervical strictures. In 8 previously perforated strictures the by-ass was performed 2 months later. Reults: The overall mortality was $4 \%$. The postoperative morbidity was low (8\%). All cervical leaks closed spontaneously. Particular late complications required revisional surgery in $12,5 \%$ of cases. Conclusion: In complicated corrosive strictures (esophageal, gastric, fistulas) limited Billoth I resection, isoperistaltic colon by-pass with high gastrocolic anastomosis, good gastric drainage and maintenance of the duodenum in gastrointestinal continuity are the main factors to achieve the best functional results.
\end{abstract}

\section{Keywords}

Complicated Corrosive Strictures, Gastric, Esophageal, Fistulas, Limited Billroth I Resection,

*Corresponding author.

"Unfortunately, this author was deceased. 


\section{Introduction}

Early and late consequences of corrosive injury may involve several segments of upper gastrointestinal tract. Although a lot of publication have been dedicated to main aspects of colonic esophageal replacemet (more than 300 up to the early 1970s) only few studies [1]-[4] are avaible on the surgical strategy in such multiple strictures. In the vast majority of previous [5] [6] and ulteriorly published coloesophageal series [7]-[10] the presence of associated strictures or respiratory fistula [10] are often mentioned without their therapeutic implications.

This study was undertaken to review our definitive surgical stategy in such instances.

\section{Patients and Method}

Among the 177 colonic substitution performed (1962-2001) for corrosive injuries (mainly by lye), 50 operation were done for complicated one, at the Surgical Department of Hospital Oradea, Romania and Thoracic Surgical Clinic at Budapest, Hungary. The type of lesions is summarised on the Table 1. The female/male ratio ammounted to 4:1, majority of patients were young (average 22.5 years). We were faced with pathologically and clinically 6 different patterns:

1) After chemical trauma, gastric emptying disturbance was the most common complication, which required to be managed whithin 2 month. Nine of such 17 patients underwent limited Billroth I resection with or without gastrostomy, but never earlier then 6 weeks after injury (Figure 1). In 3 others middle (with gastric reanastomosis) proximal or total gastrectomy were performed. The remaining 5 cases were transferred with GEA or Billroth II resection and established esophageal stricture. In these unfavorable condition for esophageal reconstruction, the first step was conversion of previous gastric operation into Billroth I one (Figure 2). In all 17 cases, except one, for associated and intractable esophageal sticture (Figure 3) a substernal by-pass with isoperistaltic transverse colon segment was done, implanted high in the gastric stump.

2) In 3 others having extensive burned and retracted gastroesophageal lesion, one-stage colonic by-pass was done in similar fashion but distally connected with the not involved prepyloric segment.

3) Combined esophageal and antro-pyloric strictures occured concomitantly in 11 young patients, on-stage limited Billroth I resection and simultaneous colonic by-pass were carried out (Figure 4).

4) For strictures extending to hypopharynx (4 patients), side-to-end pharyngo-colostomy was done (Figure 5).

5) In 7 patients onset of dysphagia was accompanied with esophagobronchial fistula symptoms, among them 3 had pyloric stricture, too. One-stage esophageal exclusion with colonic bay-pass was performed, and antrectomy for the ulteriorly mentioned cases. Only in a large respiratory fistula was necessary a second stage right sided transthoracic esophagectomy.

6) In 8 patients after unsuccessful attemps of bouginage and iatrogenic perforation, colonic by-pass was carried

Table 1. Complicated upper gastrointestinal corrosive strictures.

\begin{tabular}{|cc|}
\hline $\begin{array}{c}\text { 1962-2001 } \\
\mathrm{n}=50\end{array}$ \\
\hline type of gastric outlet stricture + esophageal stricture & no. of patients \\
\hline successive,+ , & 17 \\
concomittant,+ , & 11 \\
retracted gastric,+ , & 3 \\
high cervical & 4 \\
respiratory fistula & 4 \\
accompanied,+ , & 3 \\
after perforation & 8 \\
\hline
\end{tabular}



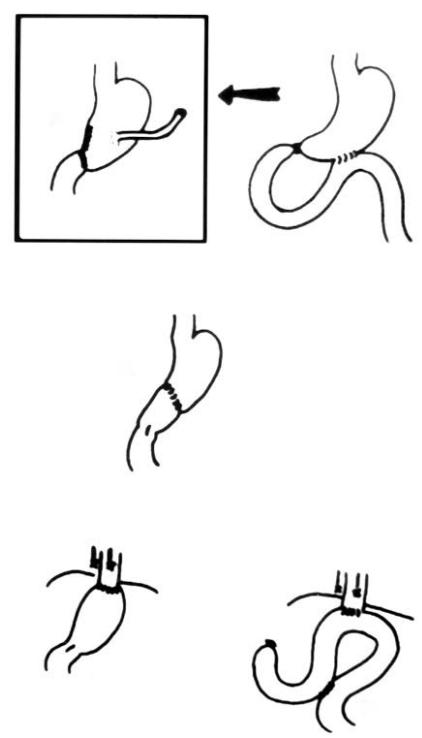

Figure 1. Types of management in corrosive gastric lesions.

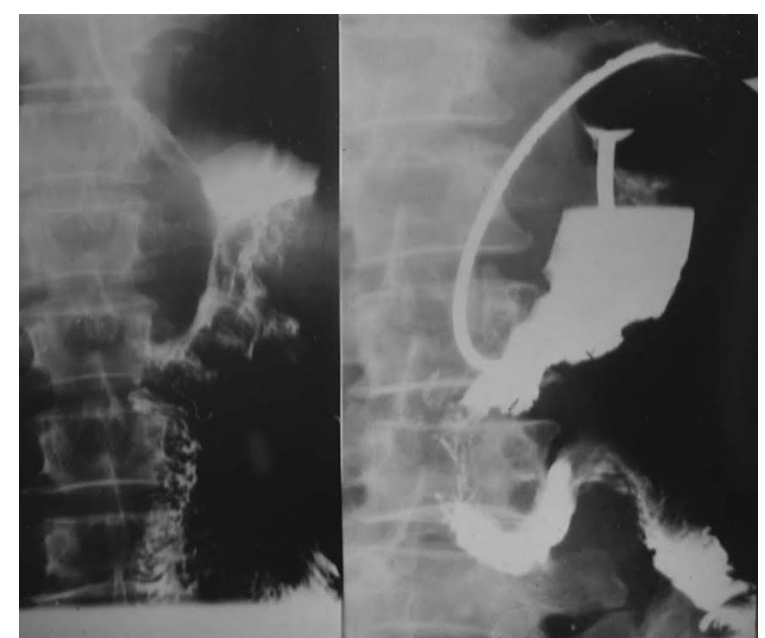

Figure 2. Aspect of antecolic GEA converted in Billoth I anastomosis.

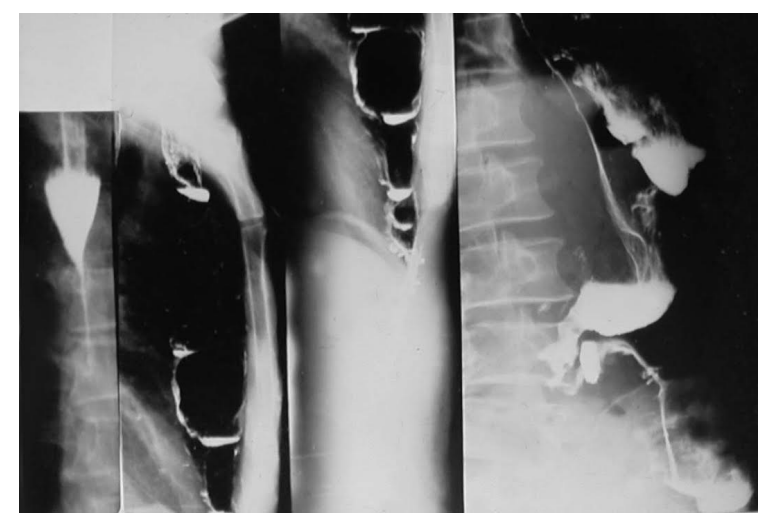

Figure 3. Aspect of substernal colonic by-pass done for the filiform esophageal stricture. 


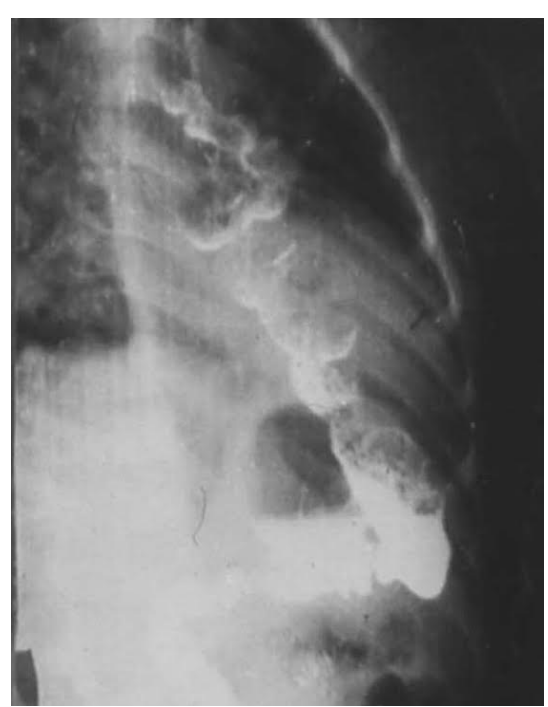

Figure 4. Aspect of Billroth I stump connected with a colonic graft.

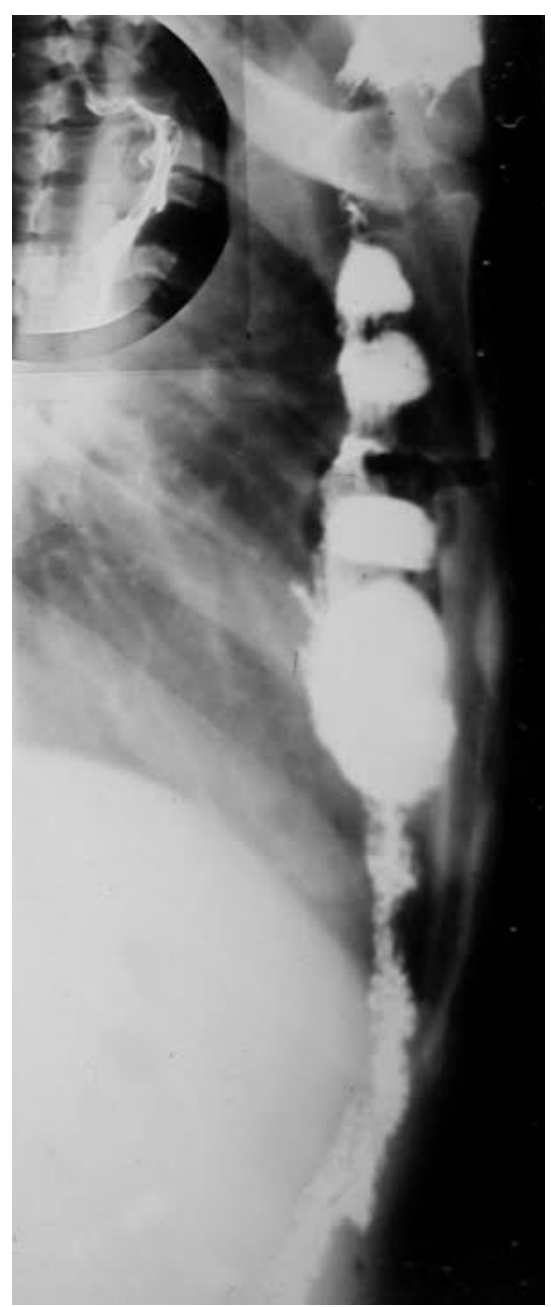

Figure 5. Aspect of substernal transverse colon segment with pharyngocolostomy. 
out after recovery, 2 - 3 month later.

\section{Main Technical Detailes}

In all instances a long, well-tailored segment from the transverse colon with its flexures was pedicled isoperistaltically (except 3) on the left colic artery and passed behinde the stomach or gastric stump and pulled to the neck through a wide substernal tunnel. Depending on the proximal level of the stricture and the quality of esophageal wall, 4 different type of proximal anastomosis have been used:

- side-to-end esophagocolostomy in case of high and severe intrathoracic strictures,

- end-to-end or side-to-end anastomosis with endoluminal occluding sutures if intact segment was above the stricture or in case of narrowed cervical esophagus,

- side-to-end pharyngocolostomy for high cervical strictures.

One-layer, interrupted suture technique was use for all type of anastomosis. Colo-colostomy was accomplished by transection of the Treitz ligament, followed by peritonisation with 2 large omental flaps. Naso-cologastric tube was used for intestinal decompression. Never was removed the damaged esophagus, except a long standing (45 years) and a fistulised esophagus.

\section{Results}

The overall mortality of the 50 patients was $4 \%$. One patient for gastrocolostomy leak and other due to cardiac failure were lost. Postoperative morbidity was low (8\%). Early complications (pneumothorax 1, cervical leak 3) were managed conservatively. Late complications (12.5\%) required revisional surgery [11]. All patients were relived from dysphagia and epigastric dyscomfort.In a normal time they have resumed a diet without restriction, expect spicy food. The transit time after swallowing the mixed barium-bread bolus was longer than that of normal subjects. The shortest transport time was noted in patients with accompanied Billroth I resection. In isoperistaltic by-pass group, gastrocolic reflux could not be produced either by the Trendelenburg position or by abdonminal compression No gastrocolic reflux have been observed except 3, having an anisoperistaltically fashioned graft. All young people from the isoperistaltic group had unimpaired growth and weight gain, among them, 3 women had complication-free pregnancies.

\section{Discussion}

There is a definitive correlation between the degree of corrosive burn and the incidense of the upper alimentary tract stricture formation. On the other hand patients with extensive gastric burne had also in $15 \%-20 \%$ cases, esophageal stricture. Only carrefully evaluated and timely indicated procedures may be usefull in surgical strategy (Table 2).

In case of combined gastroesophageal stricture, it seems clear that the delayed assessment of pyloric obstruction is usually possible in order to avoid a subsequent anastomotic stenosis. Care must be taken to avoid procedures which may affect integrity of the mesocopln with undesirable effect on an esophageal substitution. Well,

Table 2. Surgical strategy in complicated corrosive strictures.

\begin{tabular}{|c|c|c|}
\hline type of corrosive lesion & method & no. of patients \\
\hline \multirow[t]{2}{*}{${ }^{*}$ retracted gastric + esophageal } & substernal colonic by-pass & \\
\hline & with transverse colon & 3 \\
\hline \multirow[t]{2}{*}{${ }^{*}$ successive gastric + esophageal } & 1. limited gastric resection & \\
\hline & 2. by-pass with colon & 17 \\
\hline${ }^{*}$ concomittant antropyloric and & one stage limited Billroth I resection & \\
\hline esophageal & with colonic by-pass & 11 \\
\hline *hypopharygoesophageal & pharyngocologastrostomy & 4 \\
\hline${ }^{*}$ with respiratory fistula & colonic by-pass & 4 \\
\hline${ }^{*}+$ pyloric stricture & antropylorectomy + by-pass & 3 \\
\hline
\end{tabular}




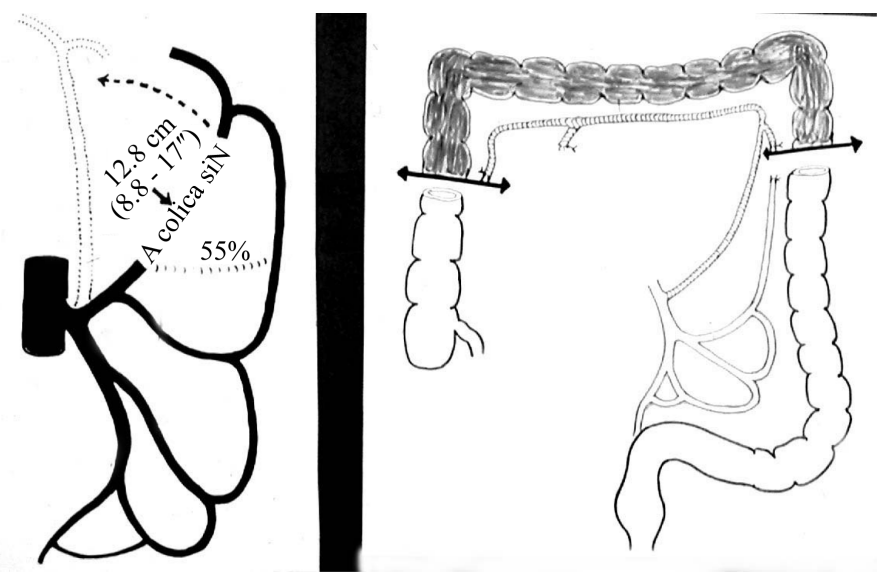

Figure 6. Illustration of the long isoperistaltic graft used in this series.

in 5 instances we were obliged to convert a previous GEA or Billroth II anastomosis into Billroth I type one. In the light of this possibility either pyloroplasty [12] or Billroth II reconstruction even antrectomy with Roux-enY gastrojejunostomy are unfavorable procedures. So the more appropriate repair is a limited Billroth I resection.

There is a controversy over whether anterior [10] or posterior [7] [9] gastrocolostomy is favorable against the gastrocolic reflux. We prefer a high anterior anastomosis as well as a not wide anastomosis (less exposed to law of communicating dishes).

To prevent the undiserable hormonal side effects of the gastric and especially duodenal exclusion, connection of the colonic graft with gastric stump is more physiologic than colojejunostomy with efferent loop [5] [6] [9].

A simple colonic by-ass with prepyloric connection for a retracted gastroesophageal lesion is more physiologic than colojejunostomy and is a less magnitude perocedure than resection. We never used augmentation gastroduodenoplasty [13] [14].

The good risk patients having a concomittant esophago-anropyloric obstruction, may considered as a special group for gastric resection and simultaneous esophageal by-pass.

There were following reasons to use different type cervical anastomosis. First is to create the best healing condition of anastomosis, second is to obtain always a sufficient anastomotic size, and third is to avoid mucocele or pseudodiverticular degeneration of the not involved esophageal segment.

A proximally sufficient large substernal tunnel (with partial division of sternocleidomastoid muscle) prove to achive a compression free tunnel. Partial resection of the thoracic outlet [9] [12] may have complications.

Opinion about wether resection or by-ass is justified in such benign lesion is not uniform. The hazard of onestage esophageal resection (transhiatal or stanadard, too) and replacemenet, especially in the presence of esophagobrochial fistula is higher than of possibility of malignat transformation. Like the majority of the authors, we prefer a lower risk procedure: a simple substernal by-pass with colon. Like Dubost, we never seen malignant scar degeneration of excluded corrosive lesion in the follow-up of the 177 patients managed by this manner. On the other hand, the danger of malignancy in long-standing such lesion [15]-[17] demands resection but as a second-step procedure.

For total by-pass the graft of choice is a transverse colon segment, pedicled on the left colic artery (Figure 6) which is a more constant artery than the middle colic one [13] [14]. Its mobilized long trunk permits a high gastric anastomosis, while the multihaustral propulsive contractions of this smaller size, active isoperistaltic colonic segment, proved to be a basic factor to prevent gastrocolic reflux [11] [18] [19]. It is well none, that reflux is common after an anisoperistaltcally fashioned graft [2]. We never observed mediastinal compression symtoms, and also incidence of the cervical leaks is fewer [4] [10] than after ileocolic grafting [10]. The smaller diameter of the paraileal vascular arch than that of paracolic one and the disfunction of the Bauchin valve may be an explanation [20].

This experience attest that in such complex corrosive lesions, a limited Billroth I resection, maintenance of the gastric sump and duodenum in the gastrointestinal continuity, a substernal and isoperistaltic straith fashioned left colonic by-pass connected with the gastric stump and good gastric emptying condition are basic factors to 
achive the best functional results.

\section{References}

[1] Dubost, C.I. (1976) Les grands brulures caustiques oeso-gastriques de l'adulte. Journal the Chirurgie, 112, 385-408.

[2] Chien, K.Y., Wang, P.Y. and Lu, K.S. (1974) Esophagoplasty for Corrosive Stricture of the Oesophagus: An Analysis of 60 Cases. Annals of Surgery, 174, 510-515.

[3] Noircler, M., Dicostanzo, J., Sastre, B., Durif, L., Fulachier, V. and Botta, D. (1984) Reconstructive Operations for Esophagogastric Corrosive Lesions. Journal of Thoracic and Cardiovascular Surgery, 97, 291-294.

[4] Wu, M.H., Tseng, Y.T., Lin, M.Y. and Lai, W.-W. (2001) Esophageal Reconstruction for Hypopharyngoesophageal Strictures after Corrosive injury. European Journal Cardio-Thoracic Surgery, 19, 400-405. http://dx.doi.org/10.1016/S1010-7940(01)00614-5

[5] Montenegro, E.B. and Cutait, D.E. (1958) Construction of a New Esophagus by Means of the Transverse Colon and Its Application for Caustic Atresia, Carcinoma and Varices of the Esophagus. Surgery, 44, 758-794.

[6] Petrov, B.A. (1964) Retrosternal Artificial Esophagus Created from Colon: 100 Operations. Surgery, 55, 520-523.

[7] Belsey, R. (1983) Reconstruction of the Esophagus. Ann R Coll Surg Engl, 65, 360-364.

[8] Wilkins, E.W. (1980) Long-Segment Colon Substitution for the Esophagus. Annals of Surgery, 192, 722-725. http://dx.doi.org/10.1097/00000658-198012000-00005

[9] DeMeester, T.R., Johnson, K.E., Franse, I., et al. (1988) Indications, Surgical Technique and Long Ter Functional Results of Colon Interposition or Bypass. Annals of Surgery, 208, 460-474. http://dx.doi.org/10.1097/00000658-198810000-00008

[10] Gerzic, Z.B., Knezevic, J.B., Milicevic, M.N. and Jovanovic, B.K. (1999) Esophagoplasty in the Management of Postcorrosive Strictures of Esophagus. Annals of Surgery, 211, 329-336. http://dx.doi.org/10.1097/00000658-199003000-00004

[11] Kotsis, L., Krisár, Z., Orbán, K. and Csekeö, A. (2002) Late Complications of Coloesophagoplasty and Long-Term Features of Adaptation. European Journal of Cardio-Thoracic Surgery, 21, 79-83.

[12] Han, Y., Cheng, Q.S., Li, X.F. and Wang, X.P. (2004) Surgical Management of Esophageal Strictures after Caustic Burns: A 30 Years of Experience. World Journal of Gastroenterology, 10, 2846-2849.

[13] Kotsis, L., Krisár, Z. and Dobjanschy, A. (1972) Angiological Basis of Coloesophagoplsty. Digest Surg, 1, 63-65.

[14] Gupta, S. (1996) Surgical Management of Corrosive Strictures Following Acid Burnes of Upper Gastrointestinal Tract. European Journal of Cardio-Thoracic Surgery, 10, 934-940. http://dx.doi.org/10.1016/S1010-7940(96)80393-9

[15] Sonneland, J., Anson, B.J. and Beaton, L.E. (1958) Surgical Anatomy of the Arterial Supply to the Colon from the Superior Mesenteric Artery Based upon a Study of 600 Specimens. Surgery, Gynecology \& Obstetrics, 106, 385-398.

[16] Nardi, G. (1957) Surgical Treatment of Lye Strictures of the Esophagus by Mediastinal Colon Transplant without Resection. New England Journal of Medicine, 75, 141-147.

[17] Imre, J. and Kopp, M. (1972) Arguments against Long Term Conservative Treatment of Esophageal Strictures Due to Corrosive Burns. Thorax, 27, 594-598. http://dx.doi.org/10.1136/thx.27.5.594

[18] Kotsis, L., Kulka, F. and Krisár, Z. (1988) Quelles sont les indications d’une chirurgie conservatrice dans les sténoses caustiques? Lésions benignes de l’ oesophag et canser. Springer-Verlag, Giuli, 770-773.

[19] Postlethwait, R.W. (1983) Colonic Interposition for Esophageal Substitution. Surgery, Gynecology \& Obstetrics, 156, 377-383.

[20] Isolauri, J. (1987) Colon Interposition in Esophagus. Thesis, Tampere Finnland. 